Rabaska

Revue d'ethnologie de l'Amérique française

BERGERON, YVES. Un patrimoine commun : les musées du

Séminaire de Québec et de l'Université Laval. Québec, Musée de la civilisation, "Les Cahiers de recherche du Musée de la civilisation », 2002, 214 p. ISBN 2-551-21661-3

\title{
Claude Corriveau
}

Volume 2, 2004

URI : https://id.erudit.org/iderudit/201658ar

DOI : https://doi.org/10.7202/201658ar

Aller au sommaire du numéro

Éditeur(s)

Société québécoise d'ethnologie

ISSN

1703-7433 (imprimé)

1916-7350 (numérique)

Découvrir la revue

Citer ce compte rendu

Corriveau, C. (2004). Compte rendu de [BERGERON, YVES. Un patrimoine commun : les musées du Séminaire de Québec et de l'Université Laval. Québec, Musée de la civilisation, "Les Cahiers de recherche du Musée de la civilisation », 2002, 214 p. ISBN 2-551-21661-3]. Rabaska, 2, 197-199.

https://doi.org/10.7202/201658ar d'utilisation que vous pouvez consulter en ligne. 
Bergeron, Yves. Un patrimoine commun : les musées du Séminaire de Québec et de l'Université Laval. Québec, Musée de la civilisation, « Les Cahiers de recherche du Musée de la civilisation », 2002, 214 p. ISBN 2-55121661-3.

Publié pour souligner le $150^{\mathrm{e}}$ anniversaire de fondation de l'université Laval, le document Un patrimoine commun : les musées du Séminaire de Québec et de l'Université Laval fait partie de la collection des « Cahiers de recherche du Musée de la civilisation ». Le cadre général de cet ouvrage est calqué sur celui de Trésors d'Amérique française paru en 1996. Il s'agit toutefois d'un document plus élaboré.

En parcourant ce volume, on s'imagine facilement en train de visiter les réserves d'un musée pour découvrir les collections accumulées au fil des siècles. L'auteur, Yves Bergeron, directeur du Service de la recherche et de l'évaluation du Musée de la civilisation à Québec, dresse dans cet ouvrage un portrait complet de l'histoire des musées et des collections du Séminaire de Québec et de l'université Laval. Ces deux grandes institutions, dédiées principalement à l'enseignement, ont un lien historique, dont un patrimoine 
en commun. D'intérêt national, ce patrimoine est constitué d'un fonds $d$ 'archives historiques, de livres rares et anciens, de collections d'objets et d'œuvres d'art ainsi que d'un ensemble architectural. À travers plus de 200 pages, l'auteur nous présente la constitution des collections du Séminaire de Québec et de l'université Laval; il démontre que ces collections sont liées au projet de création d'un musée national.

Yves Bergeron nous livre, également, de précieux renseignements sur l'histoire de la muséologie québécoise et le développement des collections $\mathrm{du} \mathrm{XVII}^{\mathrm{e}}$ siècle jusqu'à l'aube du XXI ${ }^{\mathrm{e}}$ siècle. Les différents jalons de cette histoire sont situés dans un contexte sociohistorique fort pertinent. De plus, il rend hommage aux collectionneurs qui, par leur passion, leur vision et leur acharnement, ont constitué les fondements d'importantes collections.

Cet ouvrage est composé de trois grandes parties. La première, « Genèse d'un patrimoine ", évoque les commencements de la constitution du patrimoine culturel en Nouvelle-France aux $\mathrm{XVII}^{\circ}$ et $\mathrm{XVIII}^{\mathrm{e}}$ siècles, le contexte de développement de différentes collections au Séminaire au XIX ${ }^{\mathrm{e}}$ siècle ainsi que l'apparition de divers musées et l'idée de créer un musée national à Québec. La deuxième partie, "Collections et musées », révèle l'importance et les fonctions des collections et des musées lors de la création de l'université Laval. L'auteur présente succinctement l'essor de ces musées et les principales collections. Cette synthèse est faite par regroupement typologique des musées et des collections : patrimoine scientifique, patrimoine artistique et patrimoine ethnohistorique. "Musées et identité », la troisième partie, traite du $\mathrm{XX}^{\mathrm{e}}$ siècle. L'auteur explique les différents éléments influençant la création de musées nationaux à Québec, leur croissance ainsi que les nouvelles orientations des musées et des collections du Séminaire et de l'université. Au terme de l'ouvrage, l'auteur présente une chronologie des collections du Séminaire de Québec, de 1536 à 2002. Cette chronologie, riche en information, est un complément intéressant aux chapitres précédents.

Depuis plusieurs années, Yves Bergeron s'intéresse à l'univers des collections. Cet ouvrage en témoigne : il est bien documenté et fouillé. L'auteur a basé son étude sur des sources documentaires variées, dont des documents d'archives privées. Comme le mentionne Yves Bergeron : « Ces documents patiemment accumulés m'ont permis de poser un regard neuf sur cette histoire des collections et des musées » (p. 3). Par ailleurs, l'auteur intègre dans son texte divers extraits d'auteurs traitant de la muséologie québécoise. Cette façon de faire aurait pu alourdir le texte et distraire le lecteur. Toutefois, elle est faite de manière habile et elle a le mérite de faire connaître différents travaux. L'ouvrage est illustré par une iconographie variée, composée principalement de photographies et de documents anciens. Il aurait été souhaitable que les illustrations soient davantage mises en valeur 
pour faire ressortir le prestige de ce patrimoine unique. En exposant la diversité et la richesse du patrimoine commun du Séminaire de Québec et de l'université Laval, Yves Bergeron apporte un éclairage nouveau sur l'histoire des collections, le contexte de collectionnement et le rôle des musées. Il s'agit d'un ouvrage de référence qui fait avancer la discipline, tout en étant accessible aux amants d'histoire et de culture.

Claude Corriveau

Société québécoise d'ethnologie, Québec 